\title{
Correction to: Temperature features of non-radiative energy transfer in hybrid associates of CdS/TGA quantum dots with methylene blue molecules
}

\author{
Mikhail S. Smirnov
}

Published online: 25 February 2021

(C) Springer Nature B.V. 2021

\section{Correction to: J Nanopart Res (2020) 22: 236 https://doi.org/10.1007/s11051-020-04954-z}

The original version of this article unfortunately contained a mistake in the "Funding information" section, from "This work was prepared in the framework of State support of the major scientific schools of Russian Federation (project 2613.2020.2)" to "This work was financially supported by the Ministry of Education and Science of the Russian Federation-project no. FZGU-2020-0035."

The corrected Funding information is shown below:

"This work was financially supported by the Ministry of Education and Science of the Russian Federationproject no. FZGU-2020-0035.”

Publisher's note Springer Nature remains neutral with regard to jurisdictional claims in published maps and institutional affiliations.

The online version of the original article can be found at https://doi.org/10.1007/s11051-020-04954-z

M. S. Smirnov

Voronezh State University, Voronezh 394018, Russia

M. S. Smirnov $(\square)$

Federal State Budget Educational Institution of Higher Education, Voronezh State University of Engineering Technologies,

Voronezh 394036, Russia

e-mail: smirnovms@mail.ru 